\title{
Fixed Point Results for Almost Generalized Cyclic $(\psi, \varphi)$-Weak Contractive Type Mappings with Applications
}

\author{
Mohamed Jleli, ${ }^{1}$ Erdal Karapınar, ${ }^{2}$ and Bessem Samet ${ }^{1}$ \\ ${ }^{1}$ Department of Mathematics, King Saud University, Riyadh 11451, Saudi Arabia \\ ${ }^{2}$ Department of Mathematics, Atılım University, 06836 Incek, Ankara, Turkey \\ Correspondence should be addressed to Erdal Karapınar, erdalkarapinar@yahoo.com
}

Received 8 April 2012; Accepted 9 July 2012

Academic Editor: Alexander I. Domoshnitsky

Copyright (C) 2012 Mohamed Jleli et al. This is an open access article distributed under the Creative Commons Attribution License, which permits unrestricted use, distribution, and reproduction in any medium, provided the original work is properly cited.

We define a class of almost generalized cyclic $(\psi, \phi)$-weak contractive mappings and discuss the existence and uniqueness of fixed points for such mappings. We present some examples to illustrate our results. Moreover, we state some applications of our main results in nonlinear integral equations.

\section{Introduction}

Fixed point theory is a crucial tool in the analysis of nonlinear problems. Banach contraction mapping principle [1] is the most known result in this direction: A self-mapping $T: X \rightarrow X$ on a complete metric space $(X, d)$ has a unique fixed point if there exists $k \in[0,1)$ such that $d(T x, T y) \leq k d(x, y)$ for all $x, y \in X$. In this theorem, a self-mapping $T$ is necessarily continuous. Due to its importance to fixed point theory in nonlinear analysis, desired Banach fixed point theorem have been heavily investigated by many authors (see, e.g., [2-15]). One of the remarkable generalizations of the banach contraction mapping principle was reported by Kirk et al. [16] via cyclic contraction. A mapping $T: A \cup B \rightarrow A \cup B$ is called cyclic if $T(A) \subseteq B$ and $T(B) \subseteq A$, where $A, B$ are nonempty subsets of a metric space $(X, d)$. Moreover, $T$ is called cyclic contraction if there exists $k \in(0,1)$ such that $d(T x, T y) \leq k d(x, y)$ for all $x \in A$ and $y \in B$. Notice that although a contraction is continuous, cyclic contraction need not to be. This is one of the important gains of this theorem. In this paper, the authors also introduced the following notion. 
Definition 1.1 (see [16]). Let $X$ be a nonempty set, $p$ be a positive integer, and $T: X \rightarrow X$ be a mapping. $X=\bigcup_{i=1}^{p} A_{i}$ is said to be a cyclic representation of $X$ with respect to $T$ if

(i) $A_{i}, i=1,2, \ldots, p$ are nonempty closed sets,

(ii) $T\left(A_{1}\right) \subseteq A_{2}, \ldots, T\left(A_{p-1}\right) \subseteq A_{p}, T\left(A_{p}\right) \subseteq A_{1}$.

Following the paper in [16], a number of fixed point theorems on cyclic representation of $X$ with respect to a self-mapping $T$ have appeared (see, e.g., [17-26]).

The concept of almost contractions were introduced by Berinde [27, 28]. It was shown in [27] that any strict contraction, the Kannan [12] and Zamfirescu [29] mappings, as well as a large class of quasicontractions, are all almost contractions. Almost contractions and its generalizations were further considered in several works like [7, 30-37]. Recently, Ćirić et al. [7] proved some fixed point results in ordered metric spaces using almost generalized contractive condition, which is given in the following definition.

Definition 1.2. Let $T: X \rightarrow X$ be a self-mapping on a metric space $(X, d)$. It is said to satisfy almost generalized contractive condition if there exists $k \in(0,1)$ and $L \geq 0$ such that

$$
\begin{aligned}
d(T x, T y) \leq & k \max \left\{d(x, y), d(x, T x), d(y, T y), \frac{d(x, T y)+d(y, T x)}{2}\right\} \\
& +L \min \{d(x, T x), d(y, T y), d(x, T y), d(y, T x)\},
\end{aligned}
$$

for all $x, y \in X$.

In this paper, we introduce a class of almost generalized cyclic $(\psi, \varphi)$-weak contractive mappings and we investigate the existence and uniqueness of fixed points for almost generalized cyclic $(\psi, \varphi)$-weak contractive type mappings. Our main result generalizes and improves some well-known theorems in the literature (see, e.g., [16, 18, 19, 24, 26]). We state some examples to illustrate our results. Furthermore, we apply our main result to analyze the existence and uniqueness of solutions for a class of nonlinear integral equations.

\section{Main Result}

We start this section by defining two classes of real valued functions. Let $\Phi$ be the set of functions $\varphi:[0, \infty) \rightarrow[0, \infty)$ satisfying the following conditions:

$\left(\Phi_{1}\right) \varphi$ is lower semicontinuous;

$\left(\Phi_{2}\right) \varphi^{-1}(\{0\})=\{0\}$

We denote by $\Psi$ the set of all continuous functions $\psi:[0, \infty) \rightarrow[0, \infty)$. 
Definition 2.1. Let $(X, d)$ be a metric space. Let $p$ be a positive integer and let $A_{1}, A_{2}, \ldots, A_{p}$ be nonempty subsets of $X$ and $Y=\bigcup_{i=1}^{p} A_{i}$. Let $T: Y \rightarrow Y$ be a mapping such that

(I) $Y=\bigcup_{i=1}^{p} A_{i}$ is a cyclic representation of $Y$ with respect to $T$,

(II) there exist $L \geq 0, \psi \in \Psi$ and $\varphi \in \Phi$ such that

$$
\begin{aligned}
\psi(d(T x, T y)) \leq & \psi\left(M_{T}(x, y)\right)-\varphi\left(M_{T}(x, y)\right) \\
& +L \min \{d(x, T x), d(y, T y), d(x, T y), d(y, T x)\}
\end{aligned}
$$

for all $(x, y) \in A_{i} \times A_{i+1}, i=1,2, \ldots, p$ (with $A_{p+1}=A_{1}$ ), where

$$
M_{T}(x, y):=\max \left\{d(x, y), d(T x, x), d(T y, y), \frac{d(x, T y)+d(y, T x)}{2}\right\}
$$

Then $T$ is called an almost generalized cyclic $(\psi, \varphi)$-weak contractive mapping.

Remark 2.2. Taking in the above definition, $p=1, A_{1}=X, \psi(t)=t$, and $\varphi(t)=(1-k) t$, where $k \in(0,1)$ is a constant, we obtain an almost generalized contractive condition. Then any almost generalized contractive mapping is an almost generalized cyclic $(\psi, \varphi)$-weak contractive mapping.

Our main result is the following.

Theorem 2.3. Let $\left\{A_{i}\right\}_{i=1}^{p}$ be nonempty closed subsets of a complete metric space $(X, d)$ and $Y=$ $\bigcup_{i=1}^{p} A_{i}$. Let $T: Y \rightarrow Y$ be an almost generalized cyclic $(\psi, \varphi)$-weak contractive mapping. Then $T$ has a unique fixed point that belongs to $\bigcap_{i=1}^{p} A_{i}$.

Proof. Let $x_{0} \in A_{1}$ (such a point exists since $A_{1} \neq \emptyset$ ). Define the sequence $\left\{x_{n}\right\}$ in $X$ by

$$
x_{n+1}=T x_{n}, \quad n=0,1,2, \ldots
$$

We will prove that

$$
\lim _{n \rightarrow \infty} d\left(x_{n}, x_{n+1}\right)=0
$$

If for some $k$, we have $x_{k+1}=x_{k}$, then (2.4) follows immediately. So, we can suppose that $d\left(x_{n}, x_{n+1}\right)>0$ for all $n$. From the condition (I), we observe that for all $n$, there exists $i=$ $i(n) \in\{1,2, \ldots, p\}$ such that $\left(x_{n}, x_{n+1}\right) \in A_{i} \times A_{i+1}$. Then, from the condition (II), we have

$$
\psi\left(d\left(x_{n}, x_{n+1}\right)\right) \leq \psi\left(M_{T}\left(x_{n-1}, x_{n}\right)\right)-\varphi\left(M_{T}\left(x_{n-1}, x_{n}\right)\right), \quad n=1,2, \ldots
$$


On the other hand, we have

$$
\begin{aligned}
& M_{T}\left(x_{n-1}, x_{n}\right) \\
& \quad=\max \left\{d\left(x_{n-1}, x_{n}\right), d\left(T x_{n-1}, x_{n-1}\right), d\left(T x_{n}, x_{n}\right), \frac{d\left(x_{n-1}, T x_{n}\right)+d\left(x_{n}, T x_{n-1}\right)}{2}\right\} \\
& \quad=\max \left\{d\left(x_{n-1}, x_{n}\right), d\left(x_{n}, x_{n-1}\right), d\left(x_{n+1}, x_{n}\right), \frac{d\left(x_{n-1}, x_{n+1}\right)}{2}\right\} \\
& \quad=\max \left\{d\left(x_{n-1}, x_{n}\right), d\left(x_{n+1}, x_{n}\right), \frac{d\left(x_{n-1}, x_{n+1}\right)}{2}\right\} \\
& \quad=\max \left\{d\left(x_{n-1}, x_{n}\right), d\left(x_{n+1}, x_{n}\right)\right\} .
\end{aligned}
$$

Suppose that $M_{T}\left(x_{n-1}, x_{n}\right)=d\left(x_{n+1}, x_{n}\right)$. Using (2.5), we obtain

$$
\psi\left(d\left(x_{n}, x_{n+1}\right)\right) \leq \psi\left(d\left(x_{n}, x_{n+1}\right)\right)-\varphi\left(d\left(x_{n}, x_{n+1}\right)\right)
$$

which implies that $\varphi\left(d\left(x_{n}, x_{n+1}\right)\right)=0$. From condition $\left(\Phi_{2}\right)$, we get that $d\left(x_{n}, x_{n+1}\right)=0$, a contradiction with our assumption $d\left(x_{n}, x_{n+1}\right)>0$ for all $n$. Thus, we have $M_{T}\left(x_{n-1}, x_{n}\right)=$ $d\left(x_{n-1}, x_{n}\right)$, which implies that $\left\{d\left(x_{n}, x_{n+1}\right)\right\}$ is a decreasing sequence of positive numbers. Then there exists $r \geq 0$ such that

$$
\lim _{n \rightarrow \infty} d\left(x_{n}, x_{n+1}\right)=r
$$

Letting $n \rightarrow \infty$ in (2.5), using (2.8), the continuity of $\psi$ and the lower semicontinuity of $\varphi$, we obtain

$$
\psi(r) \leq \psi(r)-\varphi(r)
$$

which implies that $\varphi(r)=0$, that is, $r=0$. Thus, we proved (2.4).

Now, we will prove that $\left\{x_{n}\right\}$ is a Cauchy sequence in $(X, d)$. Suppose that $\left\{x_{n}\right\}$ is not a Cauchy sequence. Then there exists $\varepsilon>0$ for which we can find two sequences of positive integers $\{m(k)\}$ and $\{n(k)\}$ such that for all positive integers $k$,

$$
n(k)>m(k)>k, \quad d\left(x_{m(k)}, x_{n(k)}\right) \geq \varepsilon, \quad d\left(x_{m(k)}, x_{n(k)-1}\right)<\varepsilon .
$$

Using (2.10) and the triangular inequality, we get

$$
\begin{aligned}
\varepsilon & \leq d\left(x_{n(k)}, x_{m(k)}\right) \\
& \leq d\left(x_{m(k)}, x_{n(k)-1}\right)+d\left(x_{n(k)-1}, x_{n(k)}\right) \\
& <\varepsilon+d\left(x_{n(k)}, x_{n(k)-1}\right) .
\end{aligned}
$$


Thus, we have

$$
\varepsilon \leq d\left(x_{n(k)}, x_{m(k)}\right)<\varepsilon+d\left(x_{n(k)}, x_{n(k)-1}\right) .
$$

Letting $k \rightarrow \infty$ in the above inequality and using (2.4), we obtain

$$
\lim _{k \rightarrow \infty} d\left(x_{n(k)}, x_{m(k)}\right)=\varepsilon^{+} .
$$

On the other hand, for all $k$, there exists $j(k) \in\{1, \ldots, p\}$ such that $n(k)-m(k)+j(k) \equiv 1[p]$. Then $x_{m(k)-j(k)}$ (for $k$ large enough, $m(k)>j(k)$ ) and $x_{n(k)}$ lie in different adjacently labelled sets $A_{i}$ and $A_{i+1}$ for certain $i \in\{1, \ldots, p\}$. Using (II), we obtain

$$
\begin{array}{r}
\psi\left(d\left(T x_{m(k)-j(k)}, T x_{n(k)}\right)\right) \leq \psi \\
+\left(M_{T}\left(x_{m(k)-j(k)}, x_{n(k)}\right)\right)-\varphi\left(M_{T}\left(x_{m(k)-j(k)}, x_{n(k)}\right)\right) \\
+L \min \left\{d\left(x_{m(k)-j(k)}, x_{m(k)-j(k)+1}\right), d\left(x_{n(k)}, x_{n(k)+1}\right),\right. \\
\left.d\left(x_{m(k)-j(k)}, x_{n(k)+1}\right), d\left(x_{n(k)}, x_{m(k)-j(k)+1}\right)\right\}
\end{array}
$$

for all $k$, that is,

$$
\begin{array}{r}
\psi\left(d\left(x_{m(k)-j(k)+1}, x_{n(k)+1}\right)\right) \leq \\
\psi\left(M_{T}\left(x_{m(k)-j(k)}, x_{n(k)}\right)\right)-\varphi\left(M_{T}\left(x_{m(k)-j(k)}, x_{n(k)}\right)\right) \\
+L \min \left\{d\left(x_{m(k)-j(k)}, x_{m(k)-j(k)+1}\right), d\left(x_{n(k)}, x_{n(k)+1}\right),\right. \\
\left.d\left(x_{m(k)-j(k)}, x_{n(k)+1}\right), d\left(x_{n(k)}, x_{m(k)-j(k)+1}\right)\right\},
\end{array}
$$

for all $k$. Now, we have

$$
\begin{aligned}
& M_{T}\left(x_{m(k)-j(k)}, x_{n(k)}\right) \\
& =\max \left\{d\left(x_{m(k)-j(k)}, x_{n(k)}\right), d\left(x_{m(k)-j(k)+1}, x_{m(k)-j(k)}\right), d\left(x_{n(k)+1}, x_{n(k)}\right),\right. \\
& \left.\quad \frac{d\left(x_{m(k)-j(k)}, x_{n(k)+1}\right)+d\left(x_{n(k)}, x_{m(k)-j(k)+1}\right)}{2}\right\}
\end{aligned}
$$

for all $k$. Using the triangular inequality, we get

$$
\begin{aligned}
& \left|d\left(x_{m(k)-j(k)}, x_{n(k)}\right)-d\left(x_{n(k)}, x_{m(k)}\right)\right| \\
& \quad \leq d\left(x_{\left.m(k)-j(k), x_{m(k)}\right)}\right. \\
& \quad \leq \sum_{l=0}^{j(k)-1} d\left(x_{\left.m(k)-j(k)+l, x_{m(k)-j(k)+l+1}\right)}\right. \\
& \quad \leq \sum_{l=0}^{p-1} d\left(x_{m(k)-j(k)+l}, x_{m(k)-j(k)+l+1}\right) \longrightarrow 0, \text { as } k \longrightarrow \infty \quad(\text { from }(2.4)),
\end{aligned}
$$


which implies from (2.13) that

$$
\lim _{k \rightarrow \infty} d\left(x_{m(k)-j(k)}, x_{n(k)}\right)=\varepsilon .
$$

Using (2.4), we have

$$
\begin{gathered}
\lim _{k \rightarrow \infty} d\left(x_{m(k)-j(k)+1}, x_{m(k)-j(k)}\right)=0, \\
\lim _{k \rightarrow \infty} d\left(x_{n(k)+1}, x_{n(k)}\right)=0 .
\end{gathered}
$$

Again, using the triangular inequality, we get

$$
\left|d\left(x_{m(k)-j(k)}, x_{n(k)+1}\right)-d\left(x_{m(k)-j(k)}, x_{n(k)}\right)\right| \leq d\left(x_{n(k)}, x_{n(k)+1}\right) .
$$

Letting $k \rightarrow \infty$ in the above inequality, using (2.20) and (2.18), we get

$$
\lim _{k \rightarrow \infty} d\left(x_{m(k)-j(k)}, x_{n(k)+1}\right)=\varepsilon .
$$

Similarly, we have

$$
\left|d\left(x_{n(k)}, x_{m(k)-j(k)+1}\right)-d\left(x_{m(k)-j(k)}, x_{n(k)}\right)\right| \leq d\left(x_{m(k)-j(k)}, x_{m(k)-j(k)+1}\right) .
$$

Letting $k \rightarrow \infty$, using (2.4) and (2.18), we obtain

$$
\lim _{k \rightarrow \infty} d\left(x_{n(k)}, x_{m(k)-j(k)+1}\right)=\varepsilon
$$

Similarly, we have

$$
\lim _{k \rightarrow \infty} d\left(x_{m(k)-j(k)+1}, x_{n(k)+1}\right)=\varepsilon .
$$

Now, it follows from (2.18)-(2.24) that

$$
\begin{gathered}
\lim _{k \rightarrow \infty} M_{T}\left(x_{m(k)-j(k)}, x_{n(k)}\right)=\max \left\{\varepsilon, 0,0, \frac{\varepsilon+\varepsilon}{2}\right\}=\varepsilon, \\
\lim _{k \rightarrow \infty} \min \left\{d\left(x_{m(k)-j(k)}, x_{m(k)-j(k)+1}\right), d\left(x_{n(k)}, x_{n(k)+1}\right), d\left(x_{m(k)-j(k)}, x_{n(k)+1}\right),\right. \\
\left.d\left(x_{n(k)}, x_{m(k)-j(k)+1}\right)\right\}=\min \{0,0, \varepsilon, \varepsilon\}=0 .
\end{gathered}
$$

Letting $k \rightarrow \infty$ in (2.15), using (2.25), (2.26), the continuity of $\psi$ and the lower semicontinuity of $\varphi$, we obtain

$$
\psi(\varepsilon) \leq \psi(\varepsilon)-\varphi(\varepsilon),
$$


which implies that $\varphi(\varepsilon)=0$, that is, $\varepsilon=0$, a contradiction with $\varepsilon>0$. Then we deduce that $\left\{x_{n}\right\}$ is a Cauchy sequence in the metric space $(X, d)$.

Since $(X, d)$ is complete, there exists $x^{*} \in X$ such that

$$
\lim _{n \rightarrow \infty} x_{n}=x^{*}
$$

We will prove that

$$
x^{*} \in \bigcap_{i=1}^{p} A_{i}
$$

From condition (I), and since $x_{0} \in A_{1}$, we have $\left\{x_{n p}\right\}_{n \geq 0} \subseteq A_{1}$. Since $A_{1}$ is closed, from (2.28), we get that $x^{*} \in A_{1}$. Again, from the condition (I), we have $\left\{x_{n p+1}\right\}_{n \geq 0} \subseteq A_{2}$. Since $A_{2}$ is closed, from (2.28), we get that $x^{*} \in A_{2}$. Continuing this process, we obtain (2.29).

Now, we will prove that $x^{*}$ is a fixed point of $T$. Indeed, from (2.29), since for all $n$, there exists $i(n) \in\{1,2, \ldots, p\}$ such that $x_{n} \in A_{i(n)}$, Applying (II) with $x=x^{*}$ and $y=x_{n}$, we obtain

$$
\begin{aligned}
\psi\left(d\left(T x^{*}, x_{n+1}\right)\right)= & \psi\left(d\left(T x^{*}, T x_{n}\right)\right) \\
\leq & \psi\left(M_{T}\left(x^{*}, x_{n}\right)\right)-\varphi\left(M_{T}\left(x^{*}, x_{n}\right)\right) \\
& +L \min \left\{d\left(x^{*}, T x^{*}\right), d\left(x_{n}, x_{n+1}\right), d\left(x^{*}, x_{n+1}\right), d\left(x_{n}, T x^{*}\right)\right\},
\end{aligned}
$$

for all $n$. On the other hand, we have

$$
M_{T}\left(x^{*}, x_{n}\right)=\max \left\{d\left(x^{*}, x_{n}\right), d\left(x^{*}, T x^{*}\right), d\left(x_{n}, x_{n+1}\right), \frac{d\left(x^{*}, x_{n+1}\right)+d\left(x_{n}, T x^{*}\right)}{2}\right\} .
$$

Using (2.28), we obtain that

$$
\begin{gathered}
\lim _{n \rightarrow \infty} M_{T}\left(x^{*}, x_{n}\right)=d\left(x^{*}, T x^{*}\right), \\
\lim _{n \rightarrow \infty} \min \left\{d\left(x^{*}, T x^{*}\right), d\left(x_{n}, x_{n+1}\right), d\left(x^{*}, x_{n+1}\right), d\left(x_{n}, T x^{*}\right)\right\}=0 .
\end{gathered}
$$

Letting $n \rightarrow \infty$ in (2.30), using (2.32), the continuity of $\psi$ and the lower semicontinuity of $\varphi$, we get

$$
\psi\left(d\left(x^{*}, T x^{*}\right)\right) \leq \psi\left(d\left(x^{*}, T x^{*}\right)\right)-\varphi\left(d\left(x^{*}, T x^{*}\right)\right)
$$

which implies that $d\left(x^{*}, T x^{*}\right)=0$, that is, $x^{*}$ is a fixed point of $T$.

Finally, we prove that $x^{*}$ is the unique fixed point of $T$. Assume that $y^{*}$ is another fixed point of $T$, that is, $T y^{*}=y^{*}$. From the condition (I), this implies that $y^{*} \in \bigcap_{i=1}^{p} A_{i}$. Then we can apply (II) for $x=x^{*}$ and $y=y^{*}$. We obtain

$$
\psi\left(d\left(x^{*}, y^{*}\right)\right) \leq \psi\left(M_{T}\left(x^{*}, y^{*}\right)\right)-\varphi\left(M_{T}\left(x^{*}, y^{*}\right)\right) .
$$


Since $x^{*}$ and $y^{*}$ are fixed points of $T$, we can show easily that $M_{T}\left(x^{*}, y^{*}\right)=d\left(x^{*}, y^{*}\right)$. Then we get

$$
\psi\left(d\left(x^{*}, y^{*}\right)\right) \leq \psi\left(d\left(x^{*}, y^{*}\right)\right)-\varphi\left(d\left(x^{*}, y^{*}\right)\right)
$$

which implies that $d\left(x^{*}, y^{*}\right)=0$, that is, $x^{*}=y^{*}$. Thus, we proved the uniqueness of the fixed point.

\section{Consequences}

In this section, we derive some fixed point theorems from our main result given by Theorem 2.3 .

If we take $p=1$ and $A_{1}=X$ in Theorem 2.3, then we get immediately the following fixed point theorem.

Corollary 3.1. Let $(X, d)$ be a complete metric space and $T: X \rightarrow X$ satisfies the following condition: there exist $L \geq 0, \psi \in \Psi$ and $\varphi \in \Phi$ such that

$$
\begin{aligned}
\psi(d(T x, T y)) \leq & \psi\left(M_{T}(x, y)\right)-\varphi\left(M_{T}(x, y)\right) \\
& +L \min \{d(x, T x), d(y, T y), d(x, T y), d(y, T x)\}
\end{aligned}
$$

for all $x, y \in X$. Then $T$ has a unique fixed point. Remark 2.2).

An immediate consequence of Corollary 3.1 is the following fixed point theorem (see

Corollary 3.2. Let $(X, d)$ be a complete metric space and $T: X \rightarrow X$ satisfies the following condition: there exist $L \geq 0$ and $k \in(0,1)$ such that

$$
d(T x, T y) \leq k M_{T}(x, y)+L \min \{d(x, T x), d(y, T y), d(x, T y), d(y, T x)\}
$$

for all $x, y \in X$. Then $T$ has a unique fixed point.

Remark 3.3. Taking $L=0$ in Corollary 3.1, we obtain Theorem 2.2 in [8]. Moreover, in Corollary 3.1, it is not supposed that $\psi$ is nondecreasing and $\psi^{-1}(\{0\})=\{0\}$, as in [8]. result.

Taking $\psi(t)=t, \varphi(t)=(1-k) t$, with $k \in(0,1)$, in Theorem 2.3, we derive the following 
Corollary 3.4. Let $\left\{A_{i}\right\}_{i=1}^{p}$ be nonempty closed subsets of a complete metric space $(X, d)$ and suppose that $T: \bigcup_{i=1}^{p} A_{i} \rightarrow \bigcup_{i=1}^{p} A_{i}$ satisfies the following conditions (where $A_{p+1}=A_{1}$ ):

(i) $T\left(A_{i}\right) \subseteq A_{i+1}$ for $1 \leq i \leq p$;

(ii) there exists a constant $k \in(0,1)$ such that

$$
\begin{aligned}
d(T x, T y) \leq & k \max \left\{d(x, y), d(T x, x), d(T y, y), \frac{d(x, T y)+d(y, T x)}{2}\right\} \\
& +L \min \{d(x, T x), d(y, T y), d(x, T y), d(y, T x)\},
\end{aligned}
$$

for all $(x, y) \in\left(A_{i}, A_{i+1}\right)$, for $1 \leq i \leq p$.

Then $T$ has a unique fixed point that belongs to $\bigcap_{i=1}^{p} A_{i}$.

The following fixed point theorems established in $[16,25]$ are immediate consequences of the above result.

Corollary 3.5. Let $\left\{A_{i}\right\}_{i=1}^{p}$ be nonempty closed subsets of a complete metric space $(X, d)$ and suppose that $T: \bigcup_{i=1}^{p} A_{i} \rightarrow \bigcup_{i=1}^{p} A_{i}$ satisfies the following conditions (where $A_{p+1}=A_{1}$ ):

(i) $T\left(A_{i}\right) \subseteq A_{i+1}$ for $1 \leq i \leq p$;

(ii) there exists a constant $k \in(0,1)$ such that

$$
d(T x, T y) \leq k d(x, y)
$$

for all $(x, y) \in\left(A_{i}, A_{i+1}\right)$, for $1 \leq i \leq p$.

Then $T$ has a unique fixed point that belongs to $\bigcap_{i=1}^{p} A_{i}$.

Corollary 3.6. Let $\left\{A_{i}\right\}_{i=1}^{p}$ be nonempty closed subsets of a complete metric space $(X, d)$ and suppose that $T: \bigcup_{i=1}^{p} A_{i} \rightarrow \bigcup_{i=1}^{p} A_{i}$ satisfies the following conditions (where $A_{p+1}=A_{1}$ ):

(i) $T\left(A_{i}\right) \subseteq A_{i+1}$ for $1 \leq i \leq p$;

(ii) there exists a constant $k \in(0,1)$ such that

$$
d(T x, T y) \leq \frac{k}{2}[d(x, T y)+d(y, T x)]
$$

for all $(x, y) \in\left(A_{i}, A_{i+1}\right)$, for $1 \leq i \leq p$.

Then $T$ has a unique fixed point that belongs to $\bigcap_{i=1}^{p} A_{i}$. 
Corollary 3.7. Let $\left\{A_{i}\right\}_{i=1}^{p}$ be nonempty closed subsets of a complete metric space $(X, d)$ and suppose that $T: \bigcup_{i=1}^{p} A_{i} \rightarrow \bigcup_{i=1}^{p} A_{i}$ satisfies the following conditions (where $A_{p+1}=A_{1}$ ):

(i) $T\left(A_{i}\right) \subseteq A_{i+1}$ for $1 \leq i \leq p$;

(ii) there exists a constant $k \in(0,1)$ such that

$$
d(T x, T y) \leq k \max \{d(x, T x), d(y, T y)\}
$$

for all $(x, y) \in\left(A_{i}, A_{i+1}\right)$, for $1 \leq i \leq p$.

Then $T$ has a unique fixed point that belongs to $\bigcap_{i=1}^{p} A_{i}$.

Corollary 3.8. Let $\left\{A_{i}\right\}_{i=1}^{p}$ be nonempty closed subsets of a complete metric space $(X, d)$ and suppose that $T: \bigcup_{i=1}^{p} A_{i} \rightarrow \bigcup_{i=1}^{p} A_{i}$ satisfies the following conditions (where $A_{p+1}=A_{1}$ ):

(i) $T\left(A_{i}\right) \subseteq A_{i+1}$ for $1 \leq i \leq p$;

(ii) there exist $a_{1}, a_{2}, a_{3}, a_{4}>0$ with $a_{1}+a_{2}+a_{3}+a_{4}<1$ such that

$d(T x, T y) \leq a_{1} d(x, y)+a_{2} d(T x, x)+a_{3} d(T y, y)+a_{4}\left[\frac{d(x, T y)+d(y, T x)}{2}\right]$

for all $(x, y) \in\left(A_{i}, A_{i+1}\right)$, for $1 \leq i \leq p$.

Then $T$ has a unique fixed point that belongs to $\bigcap_{i=1}^{p} A_{i}$.

Remark 3.9. Taking $p=1$ and $A_{1}=X$, we get

(i) from Corollary 3.5, the Banach contraction principle [1];

(ii) from Corollary 3.6, Kannan's fixed point theorem [12];

(iii) from Corollary 3.7, Bianchini's fixed point theorem [2] (see also [3]);

(iv) from Corollary 3.8, Hardy and Rogers fixed point theorem [9].

Now, we derive a fixed point result for cyclic mappings satisfying a contractive condition of integral type. potheses:

Denote by $\Lambda$ the set of functions $\alpha:[0, \infty) \rightarrow[0, \infty)$ satisfying the following hy-

$\left(\Lambda_{1}\right) \alpha$ is a Lebesgue integrable mapping on each compact subset of $[0, \infty)$;

$\left(\Lambda_{2}\right)$ for any $\varepsilon>0$, we have $\int_{0}^{\varepsilon} \alpha(s) d s>0$. 
We have the following result.

Corollary 3.10. Let $\left\{A_{i}\right\}_{i=1}^{p}$ be nonempty closed subsets of a complete metric space $(X, d)$ and suppose $T: \bigcup_{i=1}^{p} A_{i} \rightarrow \bigcup_{i=1}^{p} A_{i}$ satisfies the following conditions (where $A_{p+1}=A_{1}$ ):

(i) $T\left(A_{i}\right) \subseteq A_{i+1}$ for $1 \leq i \leq p$;

(ii) there exist $L \geq 0, \alpha, \beta \in \Lambda$ such that

$$
\begin{aligned}
& \int_{0}^{d(T x, T y)} \alpha(s) d s \leq \int_{0}^{M_{T}(x, y)} \alpha(s) d s-\int_{0}^{M_{T}(x, y)} \beta(s) d s \\
& +L \min \{d(x, T x), d(y, T y), d(x, T y), d(y, T x)\}, \\
& \text { for all }(x, y) \in\left(A_{i}, A_{i+1}\right) \text {, for } 1 \leq i \leq p .
\end{aligned}
$$

Then $T$ has a unique fixed point that belongs to $\bigcap_{i=1}^{p} A_{i}$.

Proof. It follows immediately from Theorem 2.3 by observing that the functions $\psi(t)=$ $\int_{0}^{t} \alpha(s) d s$ and $\varphi(t)=\int_{0}^{t} \beta(s) d s$ belong to $\Psi$.

Taking $L=0$ in Corollary 3.10, we obtain the following result.

Corollary 3.11. Let $\left\{A_{i}\right\}_{i=1}^{p}$ be nonempty closed subsets of a complete metric space $(X, d)$ and suppose $T: \bigcup_{i=1}^{p} A_{i} \rightarrow \bigcup_{i=1}^{p} A_{i}$ satisfies the following conditions (where $A_{p+1}=A_{1}$ ):

(i) $T\left(A_{i}\right) \subseteq A_{i+1}$ for $1 \leq i \leq p$;

(ii) there exist $\alpha, \beta \in \Lambda$ such that

$$
\begin{aligned}
& \qquad \int_{0}^{d(T x, T y)} \alpha(s) d s \leq \int_{0}^{M_{T}(x, y)} \alpha(s) d s-\int_{0}^{M_{T}(x, y)} \beta(s) d s, \\
& \text { for all }(x, y) \in\left(A_{i}, A_{i+1}\right), \text { for } 1 \leq i \leq p .
\end{aligned}
$$

Then $T$ has a unique fixed point that belongs to $\bigcap_{i=1}^{p} A_{i}$.

\section{Some Examples}

In this section, we give some examples to illustrate our obtained results.

Example 4.1. Let $X=[0,1]$ be endowed with the standard metric $d(x, y)=|x-y|$ for all $x, y \in X$. Consider the closed subsets $A_{1}$ and $A_{2}$ defined by $A_{1}=[0,1 / 4]$ and $A_{2}=[1 / 4,1]$. Define the mapping $T: X \rightarrow X$ by

$$
T x= \begin{cases}\frac{1}{4} & \text { if } x \in[0,1) \\ 0 & \text { if } x=1\end{cases}
$$

Clearly, we have $T\left(A_{1}\right) \subset A_{2}$ and $T\left(A_{2}\right) \subset A_{1}$. 
Now, let $(x, y) \in A_{1} \times A_{2}$. We distinguish two cases.

Case 1. If $y=1$. In this case, we have

$$
\begin{aligned}
d(T x, T y) & =|T x-T y| \\
& =\left|\frac{1}{4}-0\right| \\
& =\frac{1}{4}=\frac{1}{2} \cdot \frac{1}{2} \\
& \leq \frac{1}{2} d(y, T y) \\
& \leq \frac{1}{2} M_{T}(x, y) \\
& =M_{T}(x, y)-\frac{1}{2} M_{T}(x, y) .
\end{aligned}
$$

Define the functions $\psi, \varphi:[0, \infty) \rightarrow[0, \infty)$ by

$$
\psi(t)=t, \quad \varphi(t)=\frac{t}{2}, \quad \forall t \geq 0
$$

Then we have

$$
\psi(d(T x, T y)) \leq \psi\left(M_{T}(x, y)\right)-\varphi\left(M_{T}(x, y)\right) .
$$

Case 2. If $y \neq 1$. In this case, we have $d(T x, T y)=0$, so inequality (4.4) is satisfied.

Similarly, if $(x, y) \in A_{2} \times A_{1}$, we can show that (4.4) is satisfied.

Thus, we checked that all conditions of Theorem 2.3 are satisfied (with $p=2$ ). We deduce that $T$ has a unique fixed point $x^{*} \in A_{1} \cap A_{2}=\{1 / 4\}$.

Example 4.2. Let $X=[-\pi, \pi]$ be endowed with the standard metric $d(x, y)=|x-y|$ for all $x, y \in X$. Consider the closed subsets $A_{1}$ and $A_{2}$ defined by $A_{1}=[0, \pi]$ and $A_{2}=[-\pi, 0]$. Define the mapping $T: X \rightarrow X$ by

$$
T x= \begin{cases}-\frac{1}{3} x\left|\cos \left(\frac{1}{x}\right)\right| & \text { if } x \in[-\pi, 0) \cup(0, \pi], \\ 0 & \text { if } x=0 .\end{cases}
$$

Clearly, we have $T\left(A_{1}\right) \subset A_{2}$ and $T\left(A_{2}\right) \subset A_{1}$. 
Now, let $(x, y) \in\left(A_{1} \times A_{2}\right)$ with $x \neq 0$ and $y \neq 0$. We have

$$
\begin{aligned}
d(T x, T y) & =|T x-T y| \\
& =\left|-\frac{1}{3} x\right| \cos \left(\frac{1}{x}\right)\left|+\frac{1}{3} y\right| \cos \left(\frac{1}{y}\right)|| \\
& =\frac{1}{3}|| x|| \cos \left(\frac{1}{x}\right)|+| y|| \cos \left(\frac{1}{y}\right)|| \\
& \leq \frac{1}{3}(|x|+|y|) .
\end{aligned}
$$

On the other hand, we have

$$
\begin{gathered}
|x|=x \leq x+\frac{1}{3} x\left|\cos \left(\frac{1}{x}\right)\right|=\left|x+\frac{1}{3} x\right| \cos \left(\frac{1}{x}\right)||=d(x, T x) \\
|y|=-y \leq-y+\frac{1}{3}\left|y \cos \left(\frac{1}{y}\right)\right|=-y-\frac{1}{3} y\left|\cos \left(\frac{1}{y}\right)\right| \leq\left|y+\frac{1}{3} y\right| \cos \left(\frac{1}{y}\right)||=d(y, T y) .
\end{gathered}
$$

Then we have

$$
d(T x, T y) \leq \frac{2}{3} \max \{d(x, T x), d(y, T y)\} \leq \frac{2}{3} M_{T}(x, y) .
$$

Consider the functions $\psi, \varphi:[0, \infty) \rightarrow[0, \infty)$ defined by

$$
\psi(t)=t, \quad \varphi(t)=\frac{t}{3}, \quad \forall t \geq 0 .
$$

We have

$$
\psi(d(T x, T y)) \leq \psi\left(M_{T}(x, y)\right)-\varphi\left(M_{T}(x, y)\right) .
$$

Moreover, we can show that the above inequality holds if $x=0$ or $y=0$.

Now, all conditions of Theorem 2.3 are satisfied (with $p=2$ ), we deduce that $T$ has a unique fixed point $x^{*} \in A_{1} \cap A_{2}=\{0\}$.

\section{An Application}

In this section, we apply the result given by Theorem 2.3 to study the existence and uniqueness of solutions to a class of nonlinear integral equations.

We consider the nonlinear integral equation

$$
u(t)=\int_{0}^{1} k(t, s, u(s)) d s, \quad \forall t \in[0,1]
$$

where $k:[0,1] \times[0,1] \times \mathbb{R} \rightarrow \mathbb{R}$ is a continuous function. 
Let $X=C([0,1])$ be the set of real continuous functions on $[0,1]$. We endow $X$ with the following standard metric:

$$
d_{\infty}(u, v)=\max _{t \in[0,1]}|u(t)-v(t)|, \quad \forall u, v \in X
$$

It is well known that $\left(X, d_{\infty}\right)$ is a complete metric space. Let $(\alpha, \beta) \in X^{2}$, let $\left(\alpha_{0}, \beta_{0}\right) \in \mathbb{R}^{2}$ such that

$$
\alpha_{0} \leq \alpha \leq \beta \leq \beta_{0} .
$$

We suppose that for all $t \in[0,1]$, we have

$$
\begin{aligned}
& \alpha(t) \leq \int_{0}^{1} k(t, s, \beta(s)) d s, \\
& \beta(t) \geq \int_{0}^{1} k(t, s, \alpha(s)) d s .
\end{aligned}
$$

We suppose that for all $t, s \in[0,1], k(t, s, \cdot)$ is a decreasing function, that is,

$$
x, y \in \mathbb{R}, \quad x \geq y \Longrightarrow k(t, s, x) \leq k(t, s, y) .
$$

Finally, we suppose that for all $t, s \in[0,1]$, for all $x, y \in \mathbb{R}$ with $x \leq \beta_{0}$ and $y \geq \alpha_{0}$ or $x \geq \alpha_{0}$ and $y \leq \beta_{0}$,

$$
|k(t, s, x)-k(t, s, y)| \leq \xi(|x-y|),
$$

where $\xi:[0, \infty) \rightarrow[0, \infty)$ is continuous nondecreasing and $\varphi: t \mapsto t-\xi(t)$ belongs to $\Phi$. Now, define the set

$$
\mathcal{W}=\{u \in C([0,1]): \alpha \leq u \leq \beta\} .
$$

We have the following result.

Theorem 5.1. Under the assumptions (5.3)-(5.7), Problem (5.1) has one and only one solution $u^{*} \in$ $w$.

Proof. Define the closed subsets of $X, A_{1}$, and $A_{2}$ by

$$
\begin{aligned}
& A_{1}=\{u \in X: u \leq \beta\}, \\
& A_{2}=\{u \in X: u \geq \alpha\} .
\end{aligned}
$$


Define the mapping $T: X \rightarrow X$ by

$$
T u(t)=\int_{0}^{1} k(t, s, u(s)) d s, \quad \forall t \in[0,1] .
$$

We will prove that

$$
T\left(A_{1}\right) \subseteq A_{2}, \quad T\left(A_{2}\right) \subseteq A_{1} .
$$

Let $u \in A_{1}$, that is,

$$
u(s) \leq \beta(s), \quad \forall s \in[0,1] .
$$

Using condition (5.6), we obtain that

$$
k(t, s, u(s)) \geq k(t, s, \beta(s)), \quad \forall t, s \in[0,1] .
$$

The above inequality with condition (5.4) imply that

$$
\int_{0}^{1} k(t, s, u(s)) d s \geq \int_{0}^{1} k(t, s, \beta(s)) d s \geq \alpha(t),
$$

for all $t \in[0,1]$. Then we have $T u \in A_{2}$.

Similarly, let $u \in A_{2}$, that is,

$$
u(s) \geq \alpha(s), \quad \forall s \in[0,1] .
$$

Using condition (5.6), we obtain that

$$
k(t, s, u(s)) \leq k(t, s, \alpha(s)), \quad \forall t, s \in[0,1]
$$

The above inequality with condition (5.5) imply that

$$
\int_{0}^{1} k(t, s, u(s)) d s \leq \int_{0}^{1} k(t, s, \alpha(s)) d s \leq \beta(t),
$$

for all $t \in[0,1]$. Then we have $T u \in A_{1}$. Finally, we deduce that (5.11) holds.

Now, let $(u, v) \in A_{1} \times A_{2}$, that is, for all $t \in[0,1]$,

$$
u(t) \leq \beta(t), \quad v(t) \geq \alpha(t) .
$$

This implies from condition (5.3) that for all $t \in[0,1]$,

$$
u(t) \leq \beta_{0}, \quad v(t) \geq \alpha_{0} .
$$


Now, using condition (5.7), we can write that for all $t \in[0,1]$, we have

$$
\begin{aligned}
|T u-T v|(t) & \leq \int_{0}^{1}|k(t, s, u(s))-k(t, s, v(s))| d s \\
& \leq \int_{0}^{1} \xi(|u(s)-v(s)|) d s \\
& \leq \xi\left(d_{\infty}(u, v)\right) \quad \text { (since } \xi \text { is nondecreasing) } \\
& \leq \xi\left(M_{T}(u, v)\right) .
\end{aligned}
$$

This implies that

$$
d_{\infty}(T u, T v) \leq \xi\left(M_{T}(u, v)\right)=M_{T}(u, v)-\varphi\left(M_{T}(u, v)\right)
$$

Using the same technique, we can show that the above inequality holds also if we take $(u, v) \in$ $A_{2} \times A_{1}$.

Now, all the conditions of Theorem 2.3 are satisfied (with $\psi(t)=t$ and $L=0$ ), we deduce that $T$ has a unique fixed point $u^{*} \in A_{1} \cap A_{2}=\mathcal{W}$, that is, $u^{*} \in \mathcal{W}$ is the unique solution to (5.1).

\section{Acknowledgment}

M. Jleli and B. Samet are supported by the Research Center, College of Science, King Saud University.

\section{References}

[1] S. Banach, "Sur les opérations dans les ensembles abstraits et leur application aux equations itegrales," Fundamenta Mathematicae, vol. 3, pp. 133-181, 1922.

[2] R. M. Tiberio Bianchini, "Su un problema di S. Reich riguardante la teoria dei punti fissi," vol. 5, pp. 103-108, 1972.

[3] S. K. Chatterjea, "Fixed-point theorems," Comptes Rendus de l'Académie Bulgare des Sciences, vol. 25, pp. 727-730, 1972.

[4] Y. J. Cho, P. P. Murthy, and G. Jungck, "A common fixed point theorem of Meir and Keeler type," International Journal of Mathematics and Mathematical Sciences, vol. 16, no. 4, pp. 669-674, 1993.

[5] Y. J. Cho, P. P. Murthy, and G. Jungck, "A theorem of Meir-Keeler type revisited," International Journal of Mathematics and Mathematical Sciences, vol. 23, no. 7, pp. 507-511, 2000.

[6] Y. J. E. Cho, R. Saadati, and G. Sadeghi, "Quasi-contractive mappings in modular metric spaces," Journal of Applied Mathematics, Article ID 907951, 5 pages, 2012.

[7] L. Ćirić, M. Abbas, R. Saadati, and N. Hussain, "Common fixed points of almost generalized contractive mappings in ordered metric spaces," Applied Mathematics and Computation, vol. 217, no. 12, pp. 5784-5789, 2011.

[8] D. Dorić, "Common fixed point for generalized $(\psi, \phi)$-weak contractions," Applied Mathematics Letters, vol. 22, no. 12, pp. 1896-1900, 2009.

[9] G. E. Hardy and T. D. Rogers, "A generalization of a fixed point theorem of Reich," Canadian Mathematical Bulletin, vol. 16, pp. 201-206, 1973.

[10] G. Jungck, "Commuting mappings and fixed points," The American Mathematical Monthly, vol. 83, no. 4, pp. 261-263, 1976. 
[11] G. Jungck, "Compatible mappings and common fixed points. II," International Journal of Mathematics and Mathematical Sciences, vol. 11, no. 2, pp. 285-288, 1988.

[12] R. Kannan, "Some results on fixed points," Bulletin of the Calcutta Mathematical Society, vol. 60, pp. 71-76, 1968.

[13] A. Meir and E. Keeler, "A theorem on contraction mappings," Journal of Mathematical Analysis and Applications, vol. 28, pp. 326-329, 1969.

[14] W. Sintunavarat and P. Kumam, "Common fixed point theorems for generalized J H-operator classes and invariant approximations," Journal of Inequalities and Applications, vol. 2011, article 67, 2011.

[15] W. Sintunavarat and P. Kumam, "Generalized common fixed point theorems in complex valued metric spaces and applications," Journal of Inequalities and Applications, vol. 2012, article 84, 2012.

[16] W. A. Kirk, P. S. Srinivasan, and P. Veeramani, "Fixed points for mappings satisfying cyclical contractive conditions," Fixed Point Theory, vol. 4, no. 1, pp. 79-89, 2003.

[17] R. P. Agarwal, M. A. Alghamdi, and N. Shahzad, "Fixed point theory for cyclic generalized contractions in partial metric spaces," Fixed Point Theory and Applications, vol. 2012, article 40, 2012.

[18] E. Karapınar, "Fixed point theory for cyclic weak $\phi$-contraction," Applied Mathematics Letters, vol. 24, no. 6, pp. 822-825, 2011.

[19] E. Karapınar and K. Sadaranagni, "Fixed point theory for cyclic $(\psi, \phi)$-contractions," Fixed Point Theory and Applications, vol. 2011, asrticle 69, 2011.

[20] E. Karapınar, N. Shobkolaei, S. Sedghi, and S. M. Vaezpour, "A common fixed point theorem for cyclic operators on partial metric spaces," Filomat, vol. 26, no. 2, pp. 407-414, 2012.

[21] E. Karapınar, "Best proximity points of cyclic mappings," Applied Mathematics Letters, vol. 25, no. 11, pp. 1761-1766, 2012.

[22] E. Karapınar and İ. M. Erhan, "Cyclic contraction and fixed point theorems," Filomat, vol. 26, no. 4, pp. 777-782, 2012.

[23] E. Karapınar, İ. M. Erhan, and A. Y. Ulus, "Fixed point theorem for cyclic maps on partial metric spaces," Applied Mathematics E Information Sciences, vol. 6, no. 1, pp. 239-244, 2012.

[24] M. Păcurar and I. A. Rus, "Fixed point theory for cyclic $\phi$-contractions," Nonlinear Analysis, vol. 72, no. 3-4, pp. 1181-1187, 2010.

[25] M. A. Petric, "Some results concerning cyclical contractive mappings," General Mathematics, vol. 18, no. 4, pp. 213-226, 2010.

[26] I. A. Rus, "Cyclic representations and fixed points," Annals of the Tiberiu Popoviciu Seminar of Functional Equations, Approximation and Convexity, vol. 3, pp. 171-178, 2005.

[27] V. Berinde, "Approximating fixed points of weak contractions using the Picard iteration," Nonlinear Analysis Forum, vol. 9, no. 1, pp. 43-53, 2004.

[28] V. Berinde, "General constructive fixed point theorems for Cric-type almost contractions in metric spaces," Carpathian Journal of Mathematics, vol. 24, no. 2, pp. 10-19, 2008.

[29] T. Zamfirescu, "Fixed point theorems in metric spaces," Archiv der Mathematik, vol. 23, pp. 292-298, 1972.

[30] M. Abbas, G. V. R. Babu, and G. N. Alemayehu, “On common fixed points of weakly compatible mappings satisfying 'generalized condition (B)',"' Filomat, vol. 25, no. 2, pp. 9-19, 2011.

[31] V. Berinde and M. Păcurar, "Fixed points and continuity of almost contractions," Fixed Point Theory, vol. 9, no. 1, pp. 23-34, 2008.

[32] B. Samet and C. Vetro, "Berinde mappings in orbitally complete metric spaces," Chaos, Solitons $\mathcal{E}$ Fractals, vol. 44, no. 12, pp. 1075-1079, 2011.

[33] T. Suzuki, "Fixed point theorems for Berinde mappings," Bulletin of the Kyushu Institute of Technology. Pure and Applied Mathematics, no. 58, pp. 13-19, 2011.

[34] W. Sintunavarat and P. Kumam, "Common fixed point theorem for hybrid generalized multi-valued contraction mappings," Applied Mathematics Letters, vol. 25, pp. 52-57, 2012.

[35] W. Sintunavarat and P. Kumam, "Weak condition for generalized multi-valued $(f, \alpha, \beta)$-weak contraction mappings," Applied Mathematics Letters, vol. 24, no. 4, pp. 460-465, 2011.

[36] W. Sintunavarat and P. Kumam, "Common fixed point theorem for hybrid generalized multi-valued contraction mappings," Applied Mathematics Letters, vol. 25, no. 1, pp. 52-57, 2012.

[37] C. Mongkolkeha and P. Kumam, "Best proximity point theorems for generalized cyclic contractions in ordered metric spaces," Journal of Optimization Theory and Applications. In press. 




Advances in

Operations Research

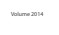

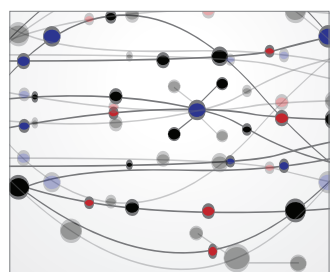

\section{The Scientific} World Journal
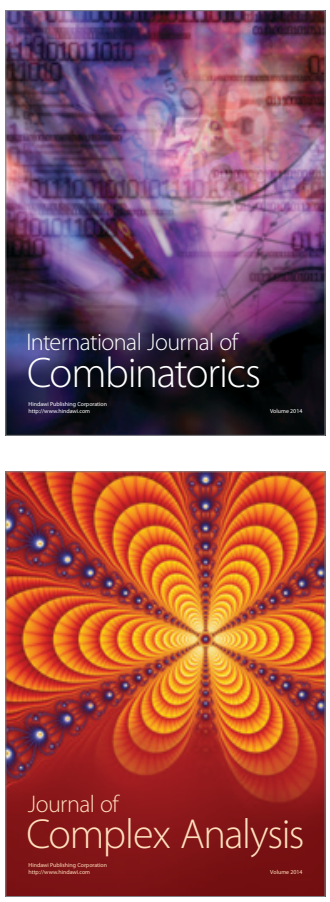

International Journal of

Mathematics and

Mathematical

Sciences
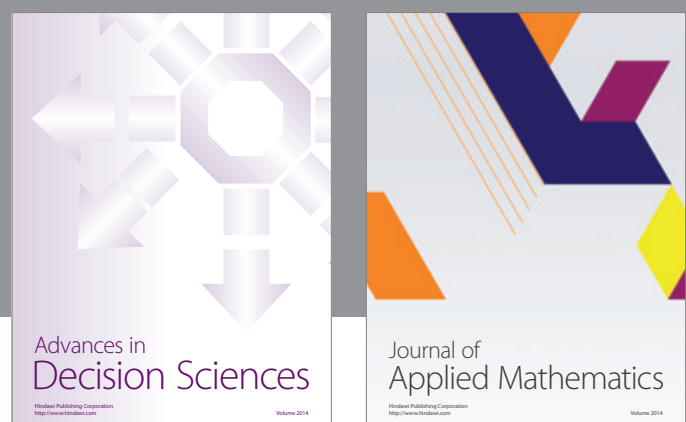

Journal of

Applied Mathematics
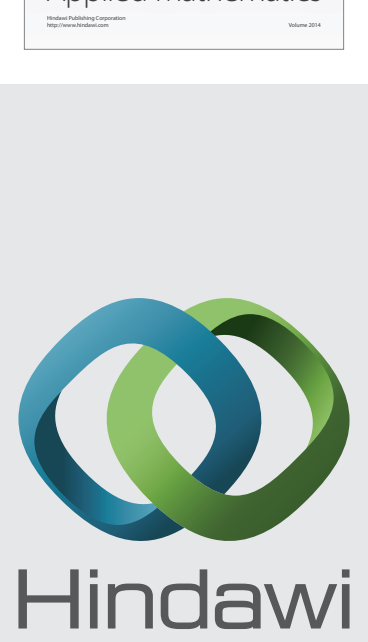

Submit your manuscripts at http://www.hindawi.com
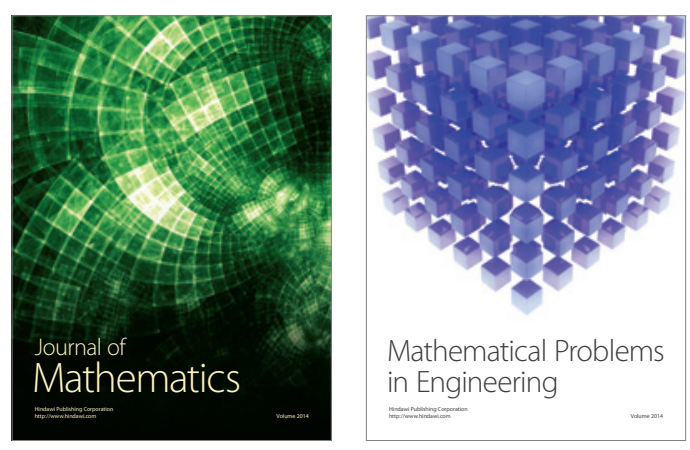

Mathematical Problems in Engineering
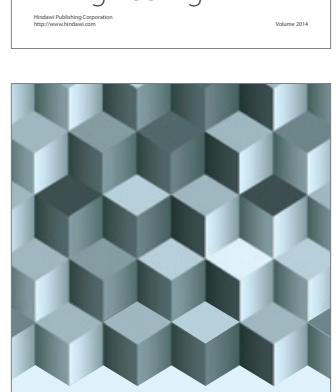

Journal of

Function Spaces
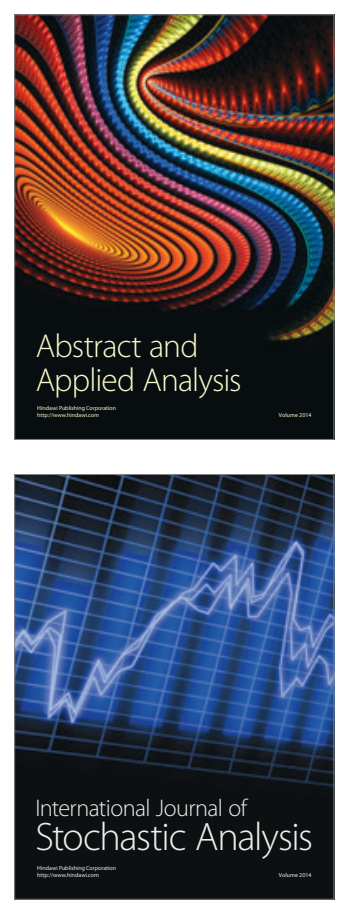



ournal of

Probability and Statistics

Promensencen
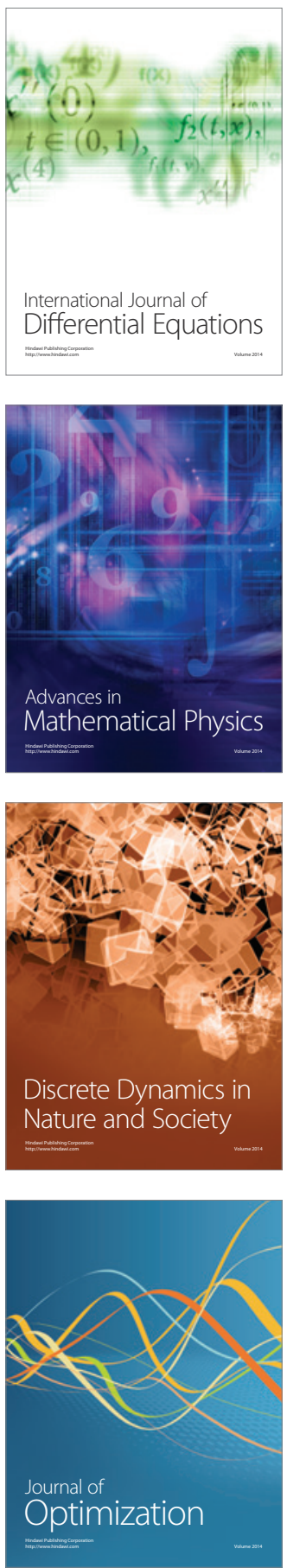